\title{
Antigénicité des protéines de soja des aliments solides chez le veau frison ou charolais pendant et après le sevrage
}

\author{
JP Lallès ${ }^{1}, Y$ Geay ${ }^{2}, M$ Brosseau ${ }^{1}$
}

Avec la collaboration technique de $R$ Jailler $^{2}$ et de E Delval ${ }^{3}$

1 INRA, laboratoire du jeune ruminant, 65, rue de Saint-Brieuc, 35042 Rennes Cedex;
2 INRA, laboratoire de la production de viande bovine, Theix, 63122 Ceyrat;
3 INRA, laboratoire de la dynamique de la digestion, Theix, 63122 Ceyrat, France

Summary - Antigenicity of soyabean proteins from concentrate feeds in Friesian and Charolais calves during and after weaning. The antigenicity of soya bean protein was studied in Friesian (FF) and Charolais $(\mathrm{CH})$ calves throughout weaning. Plasma antibody titres were higher in the FF than in the $\mathrm{CH}$ group. They decreased before weaning, increased during weaning, then did not change until 35 weeks. Positive correlations between pre- and post-treatment titres suggest an influence of colostral antibody level on the responsiveness of calves to dietary antigens.

Le veau préruminant présente à l'égard de certaines protéines (glycinine et Bconglycinine) du soja, des réactions d'intolérance qui se manifestent par des perturbations digestives et l'apparition d'anticorps systémiques spécifiques (Kilshaw et Sisson, 1979) sans que le rôle de ces derniers dans l'étiologie des troubles soit établi. Le veau en cours de sevrage produit aussi des anticorps spécifiques, lorsque ces protéines sont incorporées dans les aliments concentrés (Lallès, 1988). Nous confirmons ces résultats sur un plus grand nombre de veal'x et nous précisons la persistance du phénomène et l'influence du génotype.

Matériel et méthodes - Quarante veaux mâles de race Frisonne (FF, $n=20$ ) ou Charolaise $(\mathrm{CH}, n=20)$ ont été nourris jusqu'à l'âge de 8 semaines à l'aide d'un lait de remplacement dont les protéines provenaient en totalité du lait de vache. Ils ont ensuite été répartis en 2 lots et sevrés de la $8^{\circ}$ à la $12^{\mathrm{e}}$ semaine, à l'aide de régimes concentrés différant par la nature de l'énergie (amidon ou pulpe de betterave déshydratée) et dont les matières azotées étaient apportées principalement par du tourteau de soja (TS). Les ti- tres de glycinine et de $\beta$ conglycinine ont été mesurés dans des extraits salins d'aliments, par Elisa, à l'aide d'anticorps antiprotéines natives. Du sang jugulaire a été prélevé sur héparine entre 3 et 35 semaines (fig 1). Les titres d'anticorps plasmatiques antiprotéines de soja (APAPS), corrẻlés à ceux observés contre la glycinine et la $\beta$ conglycinine (Lallès, 1988), ont été déterminés par hémagglutination passive en utilisant un extrait salin de TS comme source d'antigènes. En raison de la perte de 6 veaux ( $1 \mathrm{FF}, 5 \mathrm{CH}$ ) en cours d'essai et de l'influence non significative $(P>0,05)$ de la nature du régime sur les titres d'APAPS, les effets de l'âge et du génotype ont été analysés par le test de Friedman et le test $U$ respectivement.

Résultats et discussion - Le TS a une forte activité antigénique in vitro car il présente des titres de glycinine et de $\beta$ conglycinine de 9 et 11, au lieu de 7 et 8 pour une farine de soja délipidée. Le titre d'APAPS n'est pas nul avant la distribution des aliments solides (fig 1), ce qui témoigne probablement de l'origine colostrale des anticorps (Kilshaw et Sissons, 1979). Cette hypothèse est renforcée par le fait que le titre d'APAPS est 2 fois plus 


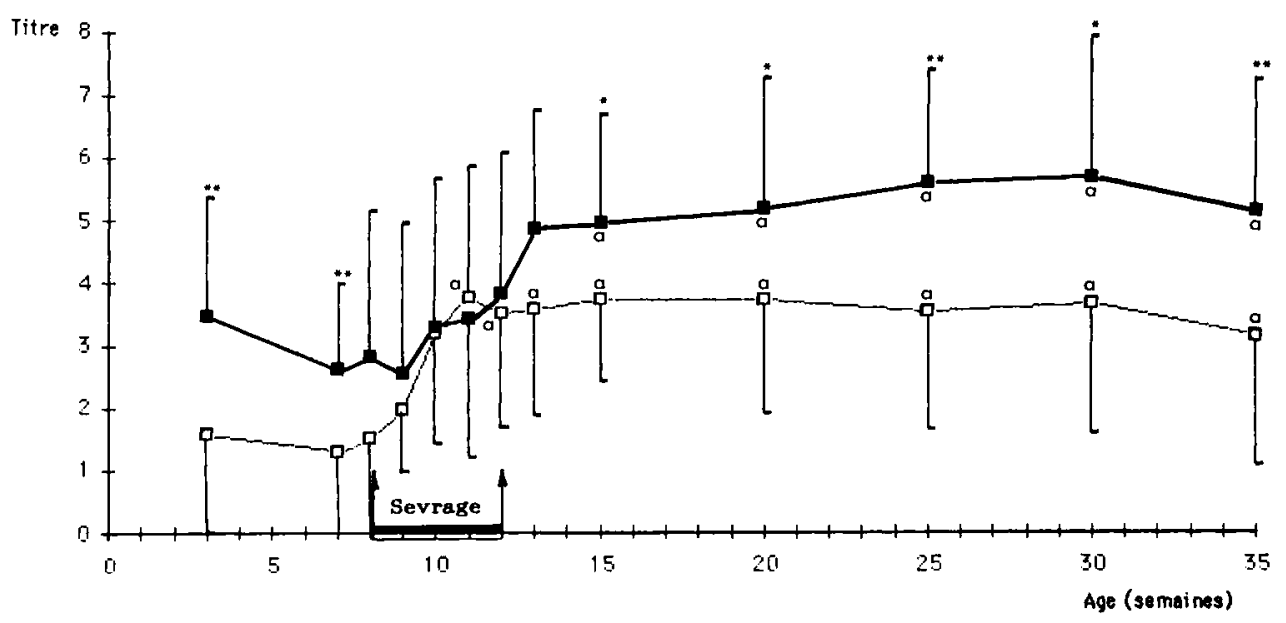

Fig 1 Évolution du titre d'anticorps antiprotéines de soja en fonction de l'âge et du génotype (* : Frison; $\square$ : Charolais), chez le veau. (a : différence significative $(P<0,05)$ par rapport au titre observé en semaine 7 ; différence entre génotypes: ${ }^{*} P<0,05$; $\left.{ }^{* *} P<0,01\right)$.

élevé dans le lot FF que dans le lot $\mathrm{CH}$, les mères Charolaises recevant plus rarement du TS. Par contre, la distribution de TS dès la $8^{\theta}$ semaine induit l'augmentation du titre d'APAPS qui atteint un plateau à partir des semaines 13 et 10 chez le veaux FF et $\mathrm{CH}$, confirmant nos précédentes observations (Lallès, 1988). II reste faible $(4,0$ en moyenne) par rapport à celui observé chez le veau préruminant sensibilisé aux protéines de soja (10 à 12 selon Kilshaw et Sissons, 1979). La moindre antigénicité de ces protéines in vivo observée dans cet essai pourrait résulter de leur dégradation plus forte dans le rumen ou d'une moindre sensibilité du veau sevré. Les veaux FF présentent, après le sevrage, un titre d'APAPS plus élevé $(P<0,01)$ que le veaux $\mathrm{CH}$ (fig 1). Les corrélations significatives entre les titres initiaux d'APAPS et ceux observés lors de la phase d'alimentation solide $(0,57<r<0,87$ et $0,52<r<0,76, P<0,01$, jusqu'à 15 semaines d'âge dans les lots FF et $\mathrm{CH}$ respectivement), suggèrent que les APAPS d'origine maternelle stimulent l'aptitude ultérieure du veau à en produire. Ces résultats sont en accord avec ceux obtenus par Barratt et al (1979) mais pas avec ceux de Heppell et al (1989) chez le veau préruminant. Chez le lapereau, les anticorps antisoja d'origine colostrale contribuent à induire une tolérance à ces mêmes protéines lorsqu'elles sont introduites dans la ration de sevrage (Pathirana et al, 1981).

En conclusion, les veaux en cours de sevrage produisent des anticorps antiprotéines de soja dont le titre reste, jusqu'à 4 mois au moins, positivement corrélé à celui observé avant toute stimulation antigénique, suggérant l'influence de l'immunité colostrale sur la réponse immunitaire ultérieure.

Barratt MEJ, Strachan PJ, Porter P (1979) Proc Nutr Soc 38, 143-150

Heppell LMJ, Sissons JW, Banks SM (1989) Res Vet Sci 47, 257-262

Kilshaw PJ, Sissons JW (1979) Res Vet Sci $27,361-365$

Lallès JP (1988) Thèse de docteur-ingénieur, ENSA, Rennes, $217 \mathrm{p}$

Pathirana C, Goulding NJ, Gibney MJ, Gallagher PJ, Pitts J, Taylor TG (1981) Proc Nutr Soc 40, 46A 